\title{
Abolition of exercise induced ST depression after exercise training and its recurrence after $\beta$ blockade
}

\author{
IAIN C TODD, JOHN B McGUINNESS, DAVID BALLANTYNE \\ From the Department of Medical Cardiology, The Victoria Infirmary, Glasgow
}

SUMMARY Exercise training can improve angina. A patient whose exercise tolerance test became normal after a year on an exercise programme nevertheless had a positive exercise test when he was taking a $\beta$ blocker.

These results suggest that it may be undesirable to use $\beta$ blockers in patients with angina who are on exercise programmes.

\section{Case report}

A 45 year old man with chronic stable angina of moderate severity for two years was enrolled in an exercise programme designed to improve his exercise tolerance. A year before he had a positive exercise test, and before he started on the exercise programme he had three more exercise tolerance tests while he was fasting. He was not on any treatment when he performed the first two tests. These two tests were identical except that on the second occasion $80 \mathrm{MBq}$ of thallium was injected one minute before the end of the exercise test and a thallium myocardial perfusion scan was obtained immediately after exercise. The

Requests for reprints to Dr Iain C Todd, Department of Clinical Medicine, The Victoria Infirmary, Glasgow G42 9TY. third test was identical with the first except that the patient had been taking $100 \mathrm{mg}$ atenolol daily for one week before the test. The last dose was taken 24 hours before the exercise test.

Treatment with atenolol was started after the third test and the patient started exercise training on the Canadian Airforce 5BX plan for physical fitness. ${ }^{1}$ In this programme the patient exercises for a maximum of 11 minutes each day at home with weekly hospital supervision. The intensity of exercise was increased each week. Within three months the patient was symptom free and within eight months he had achieved an exercise capacity in excess of that predicted for a "normal" adult of his age. The exercises were continued for a year, then the three exercise tests were repeated.

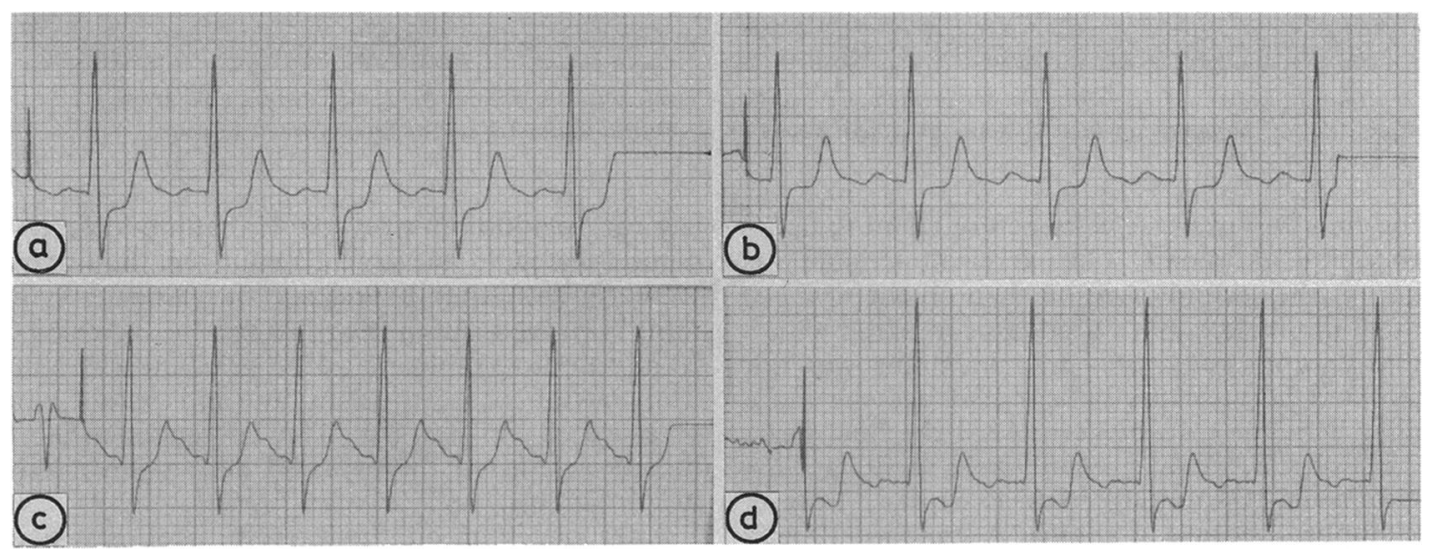

Fig 1 Electrocardiogram of lead $V$ s at the end of exercise. (a) Initial test on no drugs; (b) initial test on atenolol; (c) after training on no drugs; (d) after training on atenolol. 

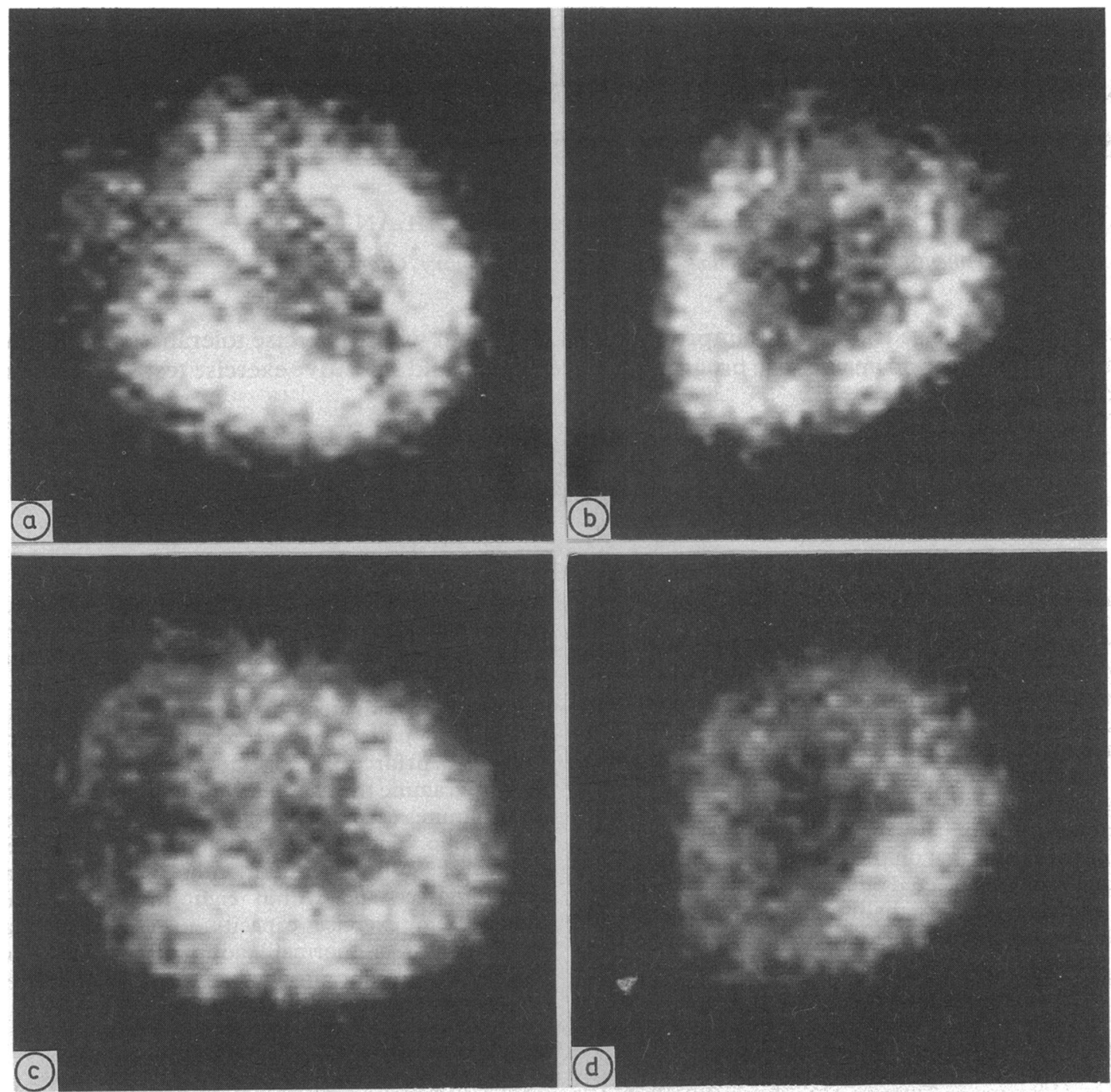

Fig 2 Thallium scans of (a) initial anterior view; (b) initial $45^{\circ}$ left anterior oblique view; (c) anterior view after training; (d) $45^{\circ}$ left anterior view showing an apical defect on the initial scan with septal defect after training.

The first two exercise tests before training had a reproducible end point. The exercise tolerance was higher on the second occasion than on the first (10 min to $3 \mathrm{mph}$ and a $7.5 \%$ gradient compared with 8 min to $3 \mathrm{mph}$ and a $5 \%$ gradient); this was not unexpected because the patient had become more familiar with the test. Nevertheless, the final heart rate and systolic blood pressure were identical (114 beats $/ \mathrm{min}$ and $180 \mathrm{~mm} \mathrm{Hg}$ ) in the two tests. The tests were stopped because of angina. A standard 12 lead electrocardiogram showed a maximum of $2 \mathrm{~mm} \mathrm{ST}$ depression in lead V4, with ST depression in V3-V5 (fig 1a). In addition, a reversible thallium defect was : demonstrated in the apical region on the anterior $\tilde{N}$ view (fig $2 a$ ). After $\beta$ blockade the patient's symp- N toms improved and in the third test he exercised for $\sigma$ 23 minutes to $3 \mathrm{mph}$ and a $15 \%$ gradient with a final 0 heart rate of 101 beats per minute and systolic blood $\stackrel{D}{\overparen{D}}$ pressure of $145 \mathrm{~mm} \mathrm{Hg}$. The test ended when he ? became exhausted; there was ST depression of $1 \mathrm{~mm}$ in V4 (fig 1b).

After one year on the exercise programme the patient was able to complete all three exercise tests without symptoms. When he was not on medication 
he could exercise to $4.5 \mathrm{mph}$ and a $25 \%$ gradient for 36 minutes. He achieved a final heart rate of 161 beats per minute and systolic blood pressure of 215 $\mathrm{mm} \mathrm{Hg}$. No ST depression was noted (fig 1c) but thallium scanning showed reversible ischaemia in the septal region on $45^{\circ}$ left anterior oblique view (fig $2 \mathrm{~d}$ ). $\beta$ blockade was again effective in reducing heart rate on exercise and the patient achieved the same end point of 36 minutes without symptoms. His final heart rate was 119 beats per minute with a systolic pressure of $190 \mathrm{~mm} \mathrm{Hg}$. Surprisingly, however, on this occasion clinically significant ST depression did occur during the test in V3-V5 with a maximum of $2 \mathrm{~mm}$ ST depression recorded, again in V4 (fig 1d).

In view of the considerable difference in cardiac work between the two thallium scans, a third thallium scan was obtained during an exercise test that was stopped at a double product equivalent to that during the first thallium scan. A comparison between this and the initial scan showed improvement in the apical defect with no proximal septal defect.

\section{Discussion}

Exercise training is used to treat angina, mainly to improve symptoms by increasing exercise tolerance. This is achieved by a reduction in resting heart rate and a reduction in heart rate and systolic blood pressure at a given exercise level after training. ${ }^{2}$ This reduces myocardial oxygen demand. It was hoped that exercise would also improve myocardial oxygen supply, perhaps by encouraging the development of collateral vessels, but there is little evidence of this. Some studies have demonstrated improved ejection fractions or thallium "scores" in individual patients. ${ }^{34}$ Recent studies have suggested that higher intensity exercise programmes for at least a year can result in real improvements in myocardial function. ${ }^{56}$ While it is not uncommon for patients to become symptom free during an exercise programme, we know of no other reports of such a dramatic improvement in an exercise tolerance test as we found in this case. Furthermore, the recurrence of exercise induced ST depression after $\beta$ blockade suggests that $\beta$ blockade after exercise training had a deleterious effect in a patient who would have been classed as a good responder to $\beta$ blockade before exercise training.

What is the explanation for the changes that we saw in this patient? Before training thallium scanning identified an area of ischaemia in the most distal region of the septum and apex. This region can be supplied by any of the three major coronary vessels.
It is also the region where collateral flow is most commonly seen and where collaterals presumably most readily develop. After training there was an improvement in this defect at the same degree of exercise while at a much higher intensity of exercise a larger defect was seen more proximally in the territory of the left anterior descending coronary artery, with relatively good perfusion at the apex. The most feasible explanation is that the major coronary stenosis lies in the proximal left anterior descending coronary artery, producing the greatest degree of ischaemia in the most distal area in its territory-that is the apex. After training the development of collaterals had improved the supply to this area but at the higher workload a more proximal area in the territory of the left anterior descending artery became ischaemic. Thallium scanning is a more sensitive indicator of ischaemia than exercise induced ST changes. ${ }^{7}$ It is not known why some patients with demonstrable ischaemia do not have ST depression. But it is reasonable to assume that the disappearance of exercise induced ST depression in this case was a result of the change in distribution of the ischaemia found on thallium scanning. (We cannot say whether the lack of ST depression implies less significant ischaemia.) If this is the explanation for the changes we saw in our patient, we can only conclude that $\beta$ blockade after exercise training produced a pattern of ischaemia that resembled the findings before training. With $\beta$ blockade myocardial oxygen consumption was similar to that achieved before training and the pattern of ST depression was identical to that seen in all three exercise tests before training. We believe that training improved perfusion by a dynamic mechanism that is susceptible to $\beta$ blockade. If the mechanism is the development of collaterals these cannot function as well under the influence of $\beta$ blockers. The improvement in treadmill time after training was maintained after $\beta$ blockade, and this suggests that the peripheral response to training is not inhibited by subsequent $\beta$ blockade. Although $\beta$ blockade prolongs exercise time, it is known to reduce maximum myocardial oxygen consumption as measured by the double product (heart rate $x$ systolic blood pressure) ${ }^{89}$ Also some patients do not respond to $\beta$ blockade. In our patient we may have demonstrated one explanation for these effects.

A training effect can be achieved in patients on $\beta$ blockers. ${ }^{10-12}$ We believe that this case shows that myocardial perfusion can be improved by exercise training and that the use of $\beta$ blockers in trained patients may not be desirable. Although we do not wish to overstate the implications of the findings in one patient we feel that they merit further investigation. 


\section{References}

1 Physical fitness. Two series of exercises developed by the Royal Canadian Air Force. Harmondsworth: Penguin Books, 1973.

2 Clausen JP, Larsen OA, Trap-Jensen J. Physical training in the management of coronary artery disease. Circulation 1969;40:143-54.

3 Verani MS, Hartung GH, Hoepfel-Harris J, Welton DE, Pratt CM, Miller RR. Effects of exercise training on left ventricular performance and myocardial perfusion in patients with coronary artery disease. $\mathrm{Am} \mathrm{J}$ Cardiol 1981;47:797-803.

4 Tubau J, Witztum K, Froelicher V, et al. Non-invasive assessment of changes in myocardial perfusion and ventricular performance following exercise training. Am Heart J 1982;104:238-48.

5 Ehsani AA, Martin WH 3rd, Heath GW, Coyle EF. Cardiac effects of prolonged and intense exercise training in patients with coronary artery disease. $\mathrm{Am} \mathrm{J}$ Cardiol 1982;50:246-54.

6 Ehsani AA, Biello DR, Schultz J, Sobel BE, Holloszy JO. Improvement of left ventricular contractile function by exercise training in patients with coronary artery disease. Circulation 1986;74: 350-8.

7 Beller GA, Watson DD, Gibson RS. Assessment of myocardial perfusion. In: Diagnostic cardiology: non-invasive imaging techniques. Philadelphia: JB Lipincott, 1984:125-49.

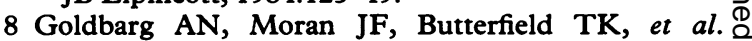
Therapy of angina pectoris with propanolol and long- in acting nitrates. Circulation 1969;40:847-53.

9 Dagenais GR, Pott B, Ross RS. Exercise tolerance in patients with angina pectoris. Daily variation and effects of erythrityl tetranitrate, propranolol and alprenolol. Am J Cardiol 1971;28:10-6.

10 Laslett LJ, Paumer L, Scott-Baier P, Amsterdam EA. Efficacy of exercise training in patients with coronary 0 artery disease who are taking propranolol. Circulation $\mathrm{N}$ 1983;68:1029-34.

11 Vanhees L, Fagard R, Amery A. Influence of beta $\mathbb{C}$ adrenergic blockade on the hemodynamic effects of 은 physical training in patients with ischemic heart disease. Am Heart J 1984;108:270-5.

12 Ehsani AA. Altered adaptive responses to training by $\frac{\mathbb{D}}{\mathrm{O}}$ non-selective beta-adrenergic blockade in coronary artery disease. Am J Cardiol 1986;58:220-4. 